\title{
Pra não dizer que não falei de flores
}

\section{Edmundo Antonio Dias ${ }^{1}$}

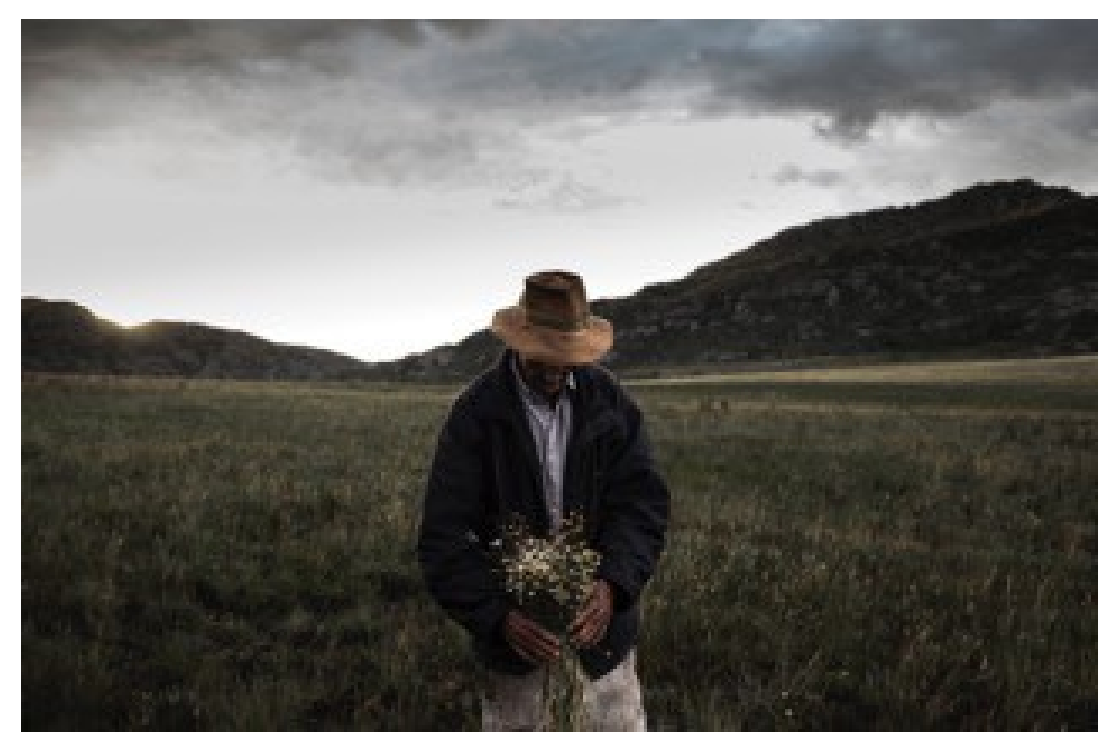

Foto de Valda Nogueira

\section{No meio do Espinhaço}

\section{Dona Jovita viu um parque}

\section{Há um parque no meio do caminho}

1 Natural de São Paulo/SP, cursou Direito na Faculdade do Largo São Francisco, da Universidade de São Paulo, e mora há muitos anos em Belo Horizonte, com a esposa Luciana e seus filhos Mariana, Bernardo, Davi e Tomás. Trabalha na área de cidadania e direitos humanos, no Ministério Público Federal, instituição que atualmente representa na Comissão Estadual de Povos e Comunidades Tradicionais de Minas Gerais, que também é composta - na fabulosa diversidade das Minas e dos Gerais - por representantes de comunidades apanhadoras de sempre-vivas. 
Sentiu as retinas fatigadas, muito Sem afastar-se, deu as mãos a Carlos Há um parque no meio do Espinhaço

As flores continuam sempre vivas

Panha de flor, roça de toco,

Pequi, cagaitê, capa-de-coco

O de antes, o por vir

Espinhaço divisor

Jequitinhonha, São Francisco abaixo

Campina-gigante, estrepa-nariz

Coinha, janeirona, chuveirinho

Brejeira, pé-de-ouro

Mata dos Crioulos, Macacos, Inhaí, Vargem do Inhaí...

Lugar de águas

Braúnas, São João da Chapada

Onde o almoço não é pra a gente só

E o sabiá no quintal come a laranja

Campina, a lapa, a Chapada

Desincomodado é onde nós fica

A Mata do Izidoro

Dona Jovita, das raízes do lugar

O entertimento das crianças no tempo da panha

E a lapa é casa 
As apanhadoras conhecem os caminhos

Do sertão à serra rebrotam sempre-vivas

Antes do parque e depois dele

Pé de Serra, Lavra, Raiz,

A campina de manhã orvalhada

O fogo no tempo certo pra não requeimar o chão

Guardar a semente

Crioula

O gado na solta

As panhadeiras conhecem os caminhos

Do sertão à serra rebrotam sempre-vivas

Antes do parque e depois dele

A Serra do azul mais escuro

Embaralhando-se com o céu

O sertão. Rosa

O sobrevoo deu o lugar da cerca-muro

No exato instante da panha de uma flor

A aeronave não reparou as mãos que a colhem

Há uma pedra no meio do caminho

De Olhos D’Água a Buenópolis

Bocaiúva a Diamantina

As borboletas ainda voam de uma flor a outra

Está decretado que devemos preservar as sempre-vivas

As apanhadoras não devem passar por nova ou velha trilha alguma 


\author{
Panhando flores, o ser \\ Exato puro \\ Desfiando a cada passo seu caminho
}

Às apanhadoras é concedido lembrarem-se das flores

Sempre vivas

Ou do tempo que o vento ao léu soprou

O parque à sua frente.

Para além da cerca-muro que sobe aos céus

Recortando a vida do sertão à serra

É preciso avisar as borboletas

Temos de interromper seus voos

A proteção total foi decretada

O pólen não deve ser levado de uma flor a outra

No interior dos muros o parque cuidará da vida

Alguma tecnologia permitirá sentir de longe seu perfume

Do Gerais à serra

As abelhas devem ser investigadas

Decretou-se, ali, um não-lugar

As apanhadoras não podem colher flores

Seu ofício não deve ser exercido

Agora não é tempo de polinizar sua poesia

Ana Carolina não deve aprender com sua mãe,

que é mistura da serra e do sertão

Tatinha não pode panhar flores 
Nem a avó, de lá da vertente do Espinhaço

Nem o avô, que é de cá, pra Diamantina

Ou Lorico, que conhece a Chapada a palmo

Nem Dona Leia, moradeira nascida e criada Em meio às belezas. Das raízes, que panham. Outro preservou não

Seu Imir e sua Vargem do Inhaí

Rama de mandioca pode não

João-velho, as penas verdes, também não

É preciso comunicar os namorados

Sobram flores nas floriculturas

É proibido subir ao campo São Domingos

Há um parque no caminho

As flores estarão sempre vivas

É preciso interromper o diálogo da panhadeira com suas flores

Está decretado que não se deve panhar flores

Tão leve gesto não se conjuga com dever

Tampouco com o ser, quando por dever deixa de ser

Apanhadoras são.

Não seriam se não panhassem sempre-vivas

O estender de suas mãos é a própria flor

O sol pretende sombrear no chão o chapéu do panhador

A namorada espera receber sua sempre-viva

Mas o caminho está fechado além da cerca 
Há lembretes espalhados

Apanhadoras não podem colher flores

Jesus-meu-deus se interroga se deve contornar o parque

Todas as multas devem ser cobradas

Só de longe se pode ouvir o trinca-ferro

Roça de toco pode não

A flor panhada não existe sem as mãos que panham

As sempre-vivas permanecerão sempre vivas

As flores não se desprenderão do solo

O parque há de reinventar a língua

O apanhador passa a ser o que não panha flores

Os dicionários revogarão os verbetes em contrário

Se joão-pobre for em direção ao tom das flores, será inevitável interromper seu voo

Não é permitido ir ao inesperado da cor mais viva de uma flor

Há implausíveis jeitos de subir a encosta

Mas são bastantes os caminhos que já foram

$\mathrm{Na}$ trilha que seria existe um parque

É preciso notificar peito-roxo da rota prefixada Mesmo se uma flor mais pálida necessitar de atenção Não será possível mudar o padrão aleatório do seu voo

No parque não há mais caminhos

Foi encontrado o algoritmo do interior dos muros

O gesto da panha de uma flor deve ser guardado na memória 
Os apanhadores palmilham demasiadas trilhas

Não se deve permitir a casualidade de sua trama

O algoritmo determina a impossibilidade dos passos

Tranquilizem-se os bichos e as cidades:

As flores estarão sempre vivas

É declarado extinto o estender das mãos do panhador de flores

Poderemos acessar fotos de flores preservadas

Será possível agendar uma visita às sempre-vivas

Os carimbos imprescindíveis serão apostos

Será mapeado o genoma da revoada das araras

Não se perderá lembrança do joão-congo nem das flores

Elas ainda estavam vivas quando o último apanhador as colheu

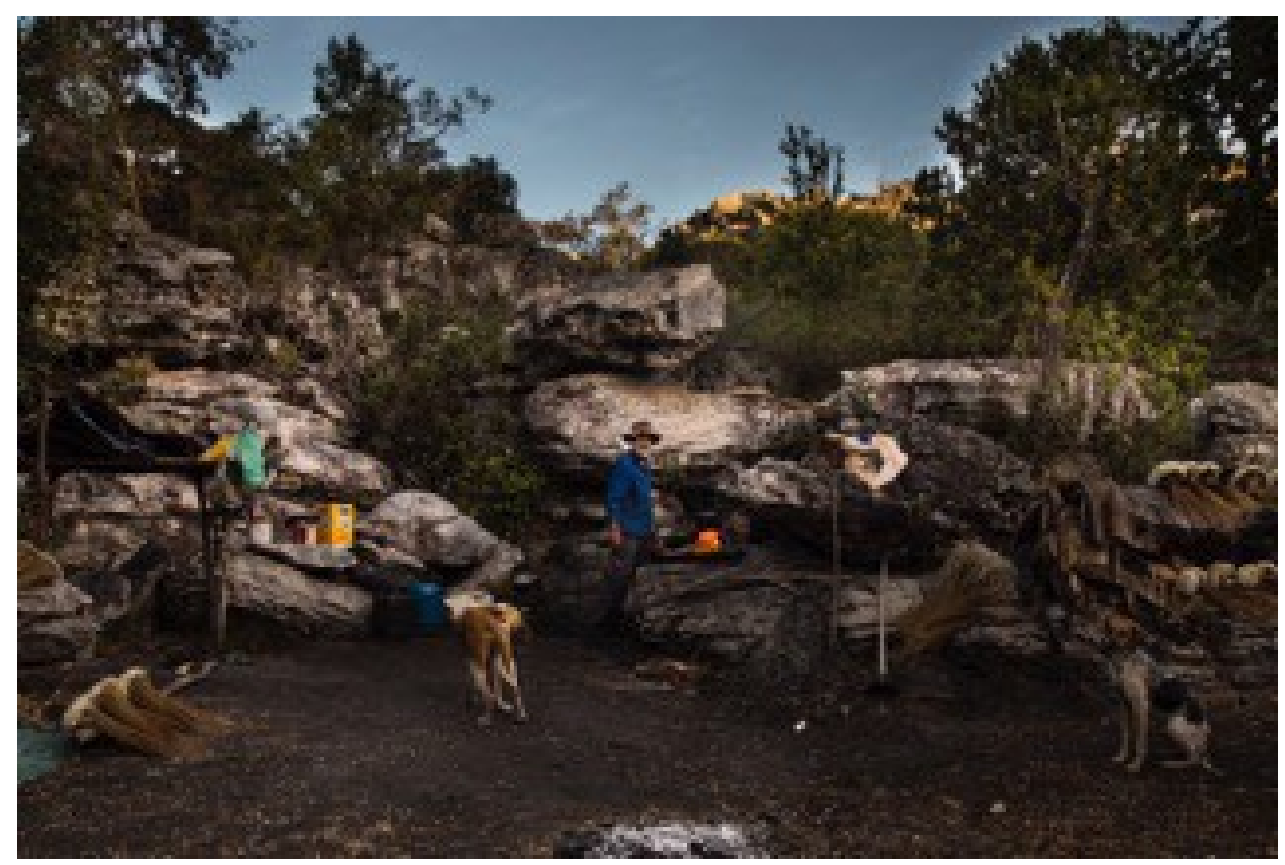

Foto de Valda Nogueira 